\title{
SITUATIONAL INFLUENCES ON QUANTITY SURVEYORS WHEN FACING ETHICAL DILEMMAS
}

\author{
Christabel M. F. Ho \\ Department of Building and Real Estate, \\ The Hong Kong Polytechnic University, \\ Hung Hom Kowloon.Hong Kong, \\ bscrysta@polyu.edu.hk
}

\begin{abstract}
This paper focuses on analyzing the impact of interest considerations of quantity surveyors on their case-specific responses, which is a direct investigation of situational influences upon decisions towards ethical dilemmas. Hypotheses are tested by rigorous statistical techniques such as Multivariate Analysis of Variance and Hierarchical Regression Analysis. It is found that the less experienced the quantity surveyors are, the more emphasis they place on the interest of their colleagues; and the more senior the membership and less educated they are, the more emphasis they would place on the interest of their employer. Moreover, given the same personal profile, the quantity surveyors can be classified as either stressing their self-interest while disregarding the interest of their employer, or emphasizing the interest of their employer while sacrificing their own interest. Post-work ethical training tools enhance quantity surveyors' emphasis on their own interest.
\end{abstract}

\section{KEYWORDS}

Professional ethics, Ethical dilemmas, Interaction effects, Ethical training

\section{INTRODUCTION}

This paper investigates how the case-specific interest considerations of quantity surveyors are affected by their background, ethical training, and interest considerations. The case studies detailed in Fan, Ho and $\mathrm{Ng}$ (2001a, 2001b) papers.

\section{RESEARCH OBJECTIVES}

The research objectives particular to this paper are:

- To explore the perceptions and decisions of quantity surveyors towards common ethical dilemmas

- To investigate the differences among subgroups of respondents and the effects of background and ethical training on their perceptions and decisions

- To investigate the interaction and moderating effects among background variables 


\section{RESEARCH METHODOLOGY}

\subsection{Research Approach}

Two case studies, which are detailed in Fan, Ho and $\mathrm{Ng}$ (2001a, 2001b) as Case 1 concerning "ghost workers" while Case 2 concerning "outside work" respectively. The following hypotheses are developed with reference to the mentioned cases.

Hypothesis 1 (H1): Quantity surveyors' considerations and decisions are different towards different ethical dilemmas, i. e. case-specific.

Hypothesis 2 (H2): The background variables of quantity surveyors strongly differentiate their ethical consideration and decision towards the same ethical dilemma.

Hypothesis 3a (H3a): The effect of membership negatively moderates that of age, education level and experience, and vice versa.

Hypothesis $3 b$ (H3b): The effect of membership positively moderates that of gender, organization type and management level, and vice versa.

Hypothesis 3c (H3c): The effect of gender negatively moderates that of age, education level, organization type, experience and management level, and vice versa.

Hypothesis 3d (H3d): The effect of age negatively moderates that of organization type and management level, and vice versa.

Hypothesis 3e (H3e): The effect of age positively moderates that of education level and experience, and vice versa.

Hypothesis $3 \mathrm{f}(\mathrm{H} 3 \mathrm{f})$ : The effect of education level negatively moderates that of organization type and management level, and vice versa.

Hypothesis $3 \mathrm{~g}$ (H3g): The effect of education level positively moderates that of experience, and vice versa.

Hypothesis $3 \mathrm{~h}$ (H3h): The effect of organization type negatively moderates that of experience, and vice versa.
Hypothesis $3 \mathrm{i}$ (H3i): The effect of organization type positively moderates that of management level, and vice versa.

Hypothesis 3j (H3j): The effect of experience negatively moderates that of management level, and vice versa.

\subsection{Sampling and Data Collection}

The population of the study is those quantity surveyors having a membership in the Quantity Surveying Division (QSD) of Hong Kong Institute of Surveyors (HKIS) and practicing in Hong Kong [1]. "Snowball" sampling method was used and the self-administered questionnaires were distributed to quantity surveyors practicing in the five types of organizations, i.e. Academy, Public Client, Private Client, Consultants and Main Contractor. The questionnaires successfully reached about $7 \%$ of the population and over $80 \%$ of the returned questionnaires are usable. The final sample size is $10 \%$ of the population.

\subsection{Measures}

All background variables are measured in Part I of the questionnaire (Fan, Ho and $\mathrm{Ng}, 2001 \mathrm{a}$ ) and the background variables include Membership (M), Gender (G), Age (A), Education Level (EL), Experience (EX), Management Level (ML) and Organization Type (O). Gender $(\mathrm{G})$ and Organization Type (O) are classified as categorical variables while the rest of background variables as ordinal variables. The seven ethical training tools selected are Prevention of Bribery Ordinance, RICS/HKIS Bye-law, RICS/HKIS Regulations, RICS Rule of Conduct for Chartered Surveyors, Corporate Code of Conduct, College Courses and CPD Courses. Quantity surveyors' perceptions towards ethical theories under casefree situation are revealed from their responses to the 4-point Likert Scale in Question 2.5. The seven ethical theories selected are Egoism, Utilitarianism, Right, Justice, Duty, Categorical Imperative and NORM. The interest considerations of quantity surveyors concern the interest of Self, Employer, Client, Superior, Colleagues (including Subordinate), Family and General Public. These interest considerations under case-free situation are reflected from Question 2.6 in Part II of the questionnaire (see Fan et al., 2001a paper). 


\section{DATA ANALYSIS METHODS}

Multivariate Analysis of Variance (MANOVA) helps indicate the differences among subgroups of various independent variables; whereas Hierarchical Regression Analysis (HRA) investigates the cause-effect relationship between variables by progressively incorporating different sets of independent variables. The three sets of hypotheses described above are tested by MANOVA and HRA. Both primary regression equations, quantity surveyors' case-specific interest considerations are set as dependent variables at the same time. More than one subsidiary regression equations are hence envisaged in each primary regression equation, which is expressed as a matrix. Model 1 includes the main effect of quantity surveyors' background variables only. The set of interaction variables showing the interaction effects of the background variables are further incorporated in Model 2. Model 3 replaces the interaction effects by ethical training effects (Question 2.3). Case-free ethical (Question 2.5) and interest (Question 2.6) considerations are included in Model 4 and 5 respectively.

\section{DISCUSSION AND CONCLUSIONS}

The research results suggest the subgroups of quantity surveyors' background variables do not have significant differences in their interest considerations for both cases. Nevertheless, it still can conclude from Case 1 that the less experienced the quantity surveyors are, the more emphasis they place on the interest of their colleagues. However, both the less educated (from Case 1) and highly educated (from Case 2) quantity surveyors are found to emphasis their self-interest. Unless the contingent nature of ethical dilemmas is highly recognized, it is neither sensible nor logical to accept the coexistence of these findings. In addition, it is also found from Case 2 that the more senior the membership and less educated they are, the more emphasis they would place on the interest of their employer. The characteristic composition of the professional population again serves as a good reason for this: the top management is usually less educated than the middle and low management level, albeit much more experienced.

As far as interaction effects are concerned, Organization Type and Age seem to induce differences in interest considerations among the subgroups of those interaction variables consisting of one of the two in Case 1 while Age and Management Level take up this role in Case 2. These interaction effects have quite different predicting power towards quantity surveyors' interest considerations for the two cases. For Case 1, they are effective in predicting quantity surveyors' interest consideration of Self while it is the case for the interest of Employer in Case 2. In case of Self-interest consideration, Organization Type positively moderates Education Level but negatively moderates Age, Experience and Management Level; Age positively moderates Experience and Management Level but negatively moderates Membership and Education Level; and Experience negatively moderates Management Level. For the interest of Employer, Organization Type and Membership positively moderate Experience and Management Level; Age positively moderates Membership and Education Level but negatively moderates Experience; and Management Level positively moderates Education Level and Experience. It is very obvious that the moderating relationships for the interest considerations of Self and Employer very often run in the opposite direction against each other [2]. This means that given the same personal profile, the quantity surveyors can be classified as either stressing their self-interest while disregarding the interest of their employer, or emphasizing the interest of their employer while sacrificing their own interest.

Ethical training is only moderately powerful in predicting quantity surveyors' interest considerations for both cases. The ethical training tools show significant effects on interest considerations of Self and General Public in Case 1 while only on interest consideration of Self in Case 2. However, for the two cases, postwork ethical training tools work well in enhancing quantity surveyors' emphasis on their own interest. It is also interesting to note from Case 2 that those quantity surveyors having studied RICS Rule of Conduct, Corporate Code of Conduct and College Courses tend to disregard their Self-interest.

Ethical schools of thought are more powerful in predicting quantity surveyors' interest considerations in Case 2 than in Case 1. Again, their predicting power in this regard is interest-specific. For Case 1, those quantity surveyors, who concern whether their ethical decisions can benefit great number of people, i.e. 
Utilitarianism, tend to emphasize their self-interest and the interest of general public. At the same time, it is interesting to note that those who generally emphasize their own interest, i.e. Egoism, tend to emphasize the interest of general public. It is argued that the quantity surveyors always take the interest of general public into account as if it is their self-interest. However, Case 2 tells an entirely different story. The more the quantity surveyors emphasize the reasoning of their ethical decisions, i.e. Right, in general, the more they would care about the interest of their family. The self-interest and the interest of employer seem to be contradictory in the mind of the quantity surveyors again. Case 2 shows that the less they prefer to the concept of NORM and Utilitarianism, the more emphasis they would place on their own interest; at the same time, the more they prefer to the concept of Utilitarianism and NORM, the more emphasis they would place on the interest of their employer. This reinforces the necessity of further investigating the conflicts between quantity surveyors' self-interest and the interest of their employer.

The predicting power of quantity surveyors' interest considerations under case-free situation is only minimal. This means that the case-free interest considerations do not always have significant impact on case-specific interest considerations. Nevertheless, those quantity surveyors who generally emphasize the interest of their colleagues would also emphasize their own interest for both cases. It is interesting to note from Case 1 that the less emphasis the quantity surveyors put on the interest of their superior and client in general, the more they would emphasize their own interest as well as the interest of colleagues. In this case, quantity surveyors' self-interest not only runs against the interest of their employer but also the interest of their client and superior.

\section{REFERENCE}

[1] 1. Fan, L., Ho, C., and Ng, V. (2001a) A Study of Quantity Surveyors' Ethical Behavior. Construction Management and Economics, 19, 19-36.

[2] 2. Fan, C. N. L., Ho, M. H. C., and Ng, V. (2001b) Effect of Professional Socialization on Quantity Surveyors' Ethical Perceptions in Hong Kong. Engineering, Construction and Architectural Management, 8, 304-312. 